\title{
UJI EFEKTIVITAS EKSTRAK MAHKOTA DEWA (Phaleria Macrocarpa) SEBAGAI REPELAN NYAMUK Aedes Aegypti
}

\author{
Rahmatullah Rayman¹, Hanna Mutiara², Betta Kurniawan², Jhons Fatriyadi² \\ ${ }^{1}$ Mahasiswa, Fakultas Kedokteran, Universitas Lampung \\ 2Departemen Parasitologi, Fakultas Kedokteran, Universitas Lampung
}

\begin{abstract}
Test Effectiveness Of Mahkota dewa's Extract (Phaleria macrocarpa) As Repellent Aedes aegypti Mosquito. Many studies show Dengue Hemorrhagic Fever (DHF) is an infectious disease that is still a threat to some areas in Indonesia caused by Aedes aegypti mosquitoes. Many ways to prevent transmission of dengue disease, one of them by using repellent. But repellent that moves in society consists of materials which are toxic when used for long periods of time. So from this problem began to look for natural materials to be made as repelan. The fruit Mahkota dewa has the active substance which is the result of its secondary metabolite which is natural as a pest repellent in the fruit. The purpose of this study is to determine the effectiveness of Mahkota dewa's extracts repellent of Aedes aegypti mosquitoes. This study was a laboratory experimental design with Randomized Complete Design (RCD) using Mahkota dewa's extract performed from October to December 2017. Aedes aegypti mosquitoes were raised in the laboratory of Zoology of University of Lampung and repellent testing was done by taking data counted 6 times using rabbits and filling in a cage containing 25 Aedes aegypti mosquitoes and then tested as repellent in the form of lotion with concentration of $0 \%, 12,5 \%, 25 \%$, and $50 \%$. The protection power of each concentration was counted and the effective concentration ( $\mathrm{EC}_{50}$ ) and effective time (ET $\left.{ }_{50}\right)$ were analyzed using probit analysis. The results showed that the extracts of mahkota dewa gave a protection power to Aedes aegypti mosquitoes. $\mathrm{EC}_{50}$ was $6,830 \%$ and $\mathrm{ET}_{50}$ was 38 minutes against Aedes aegypti mosquitoes. Mahkota dewa's extract shows having repellent activity on Aedes aegypti mosquitoes.
\end{abstract}

Keywords: Aedes aegypti, DHF, Mahkota dewa's Extract, Repellent.

\begin{abstract}
Abstrak: Uji Efektivitas Ekstrak Mahkota Dewa (Phaleria macrocarpa) Sebagai Repelan Nyamuk Aedes aegypti. Demam Berdarah Dengue (DBD) merupakan penyakit infeksi yang masih menjadi ancaman bagi beberapa daerah di Indonesia yang disebabkan oleh nyamuk Aedes aegypti. Banyak cara untuk mencegah penularan penyakit DBD salah satunya dengan menggunakan repelan. Namun repelan yang beredar di masyarakat terdiri dari bahan yang bersifat toksik bila dipakai dalam jangka waktu yang lama. Maka dari masalah ini mulai dicari bahan alami untuk dijadikan sebagai repelan. Buah mahkota dewa memiliki kandungan zat aktif yang merupakan hasil metabolit sekunder, yang alaminya berfungsi sebagai penolak hama pada buah. Tujuan penelitian ini adalah untuk mengetahui efektifitas ekstrak buah mahkota dewa sebagai repelan nyamuk Aedes aegypti. Jenis penelitian ini adalah eksperimental laboratorium dengan desain Rancangan Acak Lengkap (RAL) dengan menggunakan ekstrak mahkota dewa yang dilakukan dari bulan oktober sampai desember 2017. Nyamuk Aedes aegypti dilakukan rearing di laboratorium Zoologi Universitas Lampung dan pengujian repelan dilakukan dengan pengambilan data sebanyak 6 kali menggunakan kelinci dan dimasukkan ke dalam kurungan yang berisi 25 ekor nyamuk Aedes aegypti lalu diujikan sebagai repelan dalam bentuk lotion dengan konsentrasi $0 \%, 12,5 \%, 25 \%$, dan 50\%. Daya proteksi masing-masing konsentrasi dihitung dan estimasi konsentrasi efektif (Effective Concentration 50\%) dan waktu efektif (Effective Time 50\%) dianalisis menggunakan analisis probit. Hasil
\end{abstract}


penelitian menunjukkan ekstrak mahkota dewa memiliki daya proteksi pada nyamuk Aedes aegypti. Serta nilai $\mathrm{EC}_{50}$ adalah $6,830 \%$ dan nilai $\mathrm{ET}_{50}$ pada menit ke-38. Kesimpulan dari penelitian ini adalah ekstrak mahkota dewa menunjukkan memiliki aktivitas repelan pada nyamuk Aedes aegypti

Kata kunci: Aedes aegypti, DBD, Ekstrak Mahkota dewa, Repelan.

\section{PENDAHULUAN}

Nyamuk secara aspek klinik memiliki peran penting sebagai sumber penularan penyakit. Nyamuk Aedes Aegypti memiliki peran penting sebagai vektor penyakit Demam Berdarah Dengue (DBD)(Perkins, 2011). WHO mencatat negara Indonesia sebagai negara dengan kasus DBD tertinggi di Asia Tenggara. Saat ini pencegahan terhadap nyamuk yang paling umum adalah menggunakan racun kimia diantaranya bahan penolak nyamuk (repelan). Hampir semua lotion dan spray anti nyamuk yang beredar di Indonesia berbahan aktif Diethyl Metatoluamid (DEET) yang merupakan bahan kimia sintetis beracun dalam konsentrasi 10-15\% (WHO, 2012).

Berdasarkan hal tersebut dibutuhkan pemanfaatan ekstrak tumbuhan untuk mencegah gigitan nyamuk yang lebih alami dan dirasa lebih aman karena memiliki residu yang pendek dan efek samping yang jauh lebih kecil bagi manusia (Novizan, 2002). Terdapat banyak tumbuhan yang berpotensi menjadi pestisida alami ini, salah satunya mahkota dewa(Mustanir, 2011).

Buah mahkota dewa mengandung senyawa bioaktif seperti alkaloid, flavonoid, saponin, tannin, fenol, lignan, sterol, dan minyak atsiri sehingga dapat digunakan sebagai insektisida. Minyak atsiri dengan komponen limonene, mirsen, linalool, oktanal, decanal, sitronelol, neral, geraniol, valansen, sinsial, dan sinensial. Linalool, sitronelol, geraniol termasuk senyawa yang bersifat repelen bagi arthropoda(Harmanto, 2004).

Penggunaan bahan alami dari ekstrak mahkota dewa diharapkan lebih aman jika dibandingkan dengan bahan kimia DEET. Berdasarkan penelitian diatas, maka pada penelitian ini akan dikaji kemampuan ekstrak mahkota dewa (Phaleria Macrocarpa) untuk menolak nyamuk Aedes aegypti terkait lama waktu dan kemampuan daya tolaknya (Auliaet al, 2013).

\section{METODE}

Penelitian yang dilakukan ini bersifat eksperimental laboratorik. Dalam penelitian ini, buah mahkota dewa akan diambil ekstraknya, nantinya ekstrak buah mahkota dewa dibuat berbagai macam konsentrasi yang diinginkan pada lotion. Setelah terbentuk konsentrasi yang diinginkan, mula-mula kelinci akan dicukur punggungnya seluas $3 \times 4 \mathrm{~cm}^{2}$ lalu setelah itu akan dioleskan lotion dengan kadar ekstrak buah mahkota dewa kelompok pertama dengan kadar ekstrak mahkota dewa $0 \%$ lalu dimasukkan kedalam kandang nyamuk yang berisi 25 ekor dan diamati selama 3 menit. Kemudian dikeluarkan dari kandang dan dimasukkan lagi pada jam perlakuan berikutnya sampai enam jam perlakuan setiap 30 menit, 1 jam, 2 jam, 4 jam, dan 6 jam setelah perlakuan pertama, dengan lama pengamatan sama yaitu 3 menit. Nyamuk dan kandang yang digunakan pada pengambilan data kedua dan seterusnya merupakan nyamuk dan kandang yang berbeda dengan yang pertama, namun dengan jumlah yang sama yaitu 25 ekor(WHOPES, 2000).

Pada kelompok kedua yaitu dengan kadar ekstrak mahkota dewa 12,5\% dioleskan pada punggung kelinci yang sudah dicukur sebelumnya, lalu dimasukkan ke kandang dan diamati selama 3 menit, lalu selanjutnya dikeluarkan dan dimasukkan lagi pada pada 30 menit, 1 jam, 2 jam, 4 jam, dan 6 jam setelah 
perlakuan pertama dan diamati selama 3 menit setiap pengambilan data. Pada dua kelompok lainnya yaitu $25 \%$ dan $50 \%$ juga dilakukan pengambilan data dengan prosedur yang sama dengan menggunakan nyamuk yang berbeda dan kandang yang berbeda. Jadi setiap 1 kelompok percobaan menggunakan 6 kandang nyamuk dan 25 ekor nyamuk yang berbeda juga pada setiap kandangnya. Setelah itu dihitung persentase daya proteksi dinilai pada akhir pengujian, sebagai proporsi jumlah nyamuk yang hinggap pada hewan coba perlakuan dengan jumlah nyamuk yang hinggap pada hewan coba kontrol, dihitung dengan formula berikut :

\section{HASIL}

Data yang didapat pada penelitian berupa jumlah nyamuk Aedes aegypti yang kontak dengan hewan coba kontrol dan kelompok perlakuan (Tabel 1). Kelompok 1 merupakan kontrol negatif yaitu lotion dengan kadar ekstrak buah mahkota dewa $0 \%$. Jumlah nyamuk yang kontak pada konsentrasi $0 \%$
Persentase Daya Proteksi (\%) =

$$
\frac{\sum C-\sum \quad T}{\sum \quad C} \times 100 \%
$$

Keterangan:

$\Sigma \mathrm{C}=$ jumlah nyamuk kontak pada lengan kontrol

$\Sigma T=$ jumlah nyamuk kontak pada lengan perlakuan

Setelah didapatkan persentase daya proteksi pada masing-masing konsentrasi dinilai konsentrasi yang efektif untuk memperoleh persentase daya proteksi yang paling baik.Selanjutnya dilakukan analisis probit untuk mengetahui konsentrasi dan waktu yang efektif dari ekstrak mahkota dewa pada aktivitas nyamuk dewasa Aedes aegypti yang dinyatakan dengan $\mathrm{EC}_{50}$ dan $\mathrm{ET}_{50}($ WHOPES, 2000).

(kontrol negatif) dinyatakan baik bila jumlahnya $\geq 10$ ekor sehingga pada penelitian ini menunjukkan hasil yang baik. Kemudian dihitung persentase daya proteksi pada masing-masing konsentrasi ekstrak buah mahkota dewa berdasarkan jumlah nyamuk yang kontak pada kontrol negatif (Tabel 2).

Tabel 1. Jumlah Nyamuk Yang Kontak Dengan Hewan Coba

\begin{tabular}{ccccccc}
\hline \multirow{2}{*}{ Kelompok } & \multicolumn{7}{c}{ Pengambilan Data Ke- } \\
\cline { 2 - 7 } & $\begin{array}{c}\text { 1 Menit } \\
\text { ke- 1 }\end{array}$ & $\begin{array}{c}\text { 2 Menit } \\
\text { ke- 30 }\end{array}$ & $\begin{array}{c}\text { 3 Menit } \\
\text { ke- 60 }\end{array}$ & $\begin{array}{c}\text { 4 Menit } \\
\text { ke- 120 }\end{array}$ & $\begin{array}{c}\text { 5 Menit } \\
\text { ke- 240 }\end{array}$ & $\begin{array}{c}\text { 6 Menit } \\
\text { ke- 360 }\end{array}$ \\
\hline 1 & 25 & 30 & 29 & 32 & 28 & 27 \\
2 & 9 & 10 & 8 & 11 & 8 & 7 \\
3 & 8 & 6 & 7 & 7 & 5 & 6 \\
4 & 4 & 3 & 3 & 4 & 2 & 2 \\
\hline
\end{tabular}

Tabel 2. Persentase Daya Proteksi Ekstrak Buah Mahkota Dewa Pada Hewan Coba

\begin{tabular}{ccccccc}
\hline \multirow{2}{*}{ Kelompok } & \multicolumn{7}{c}{ Persentase Daya Proteksi } \\
\cline { 2 - 7 } & $\begin{array}{c}\text { 1 Menit } \\
\text { ke- 1 }\end{array}$ & $\begin{array}{c}\text { 2 Menit } \\
\text { ke- 30 }\end{array}$ & $\begin{array}{c}\mathbf{3} \text { Menit } \\
\text { ke- 60 }\end{array}$ & $\begin{array}{c}\text { 4 Menit } \\
\text { ke- 120 }\end{array}$ & $\begin{array}{c}\mathbf{5} \text { Menit } \\
\text { ke- 240 }\end{array}$ & $\begin{array}{c}\text { 6 Menit } \\
\text { ke- 360 }\end{array}$ \\
\hline 1 & - & - & - & - & - & - \\
2 & $64 \%$ & $66,66 \%$ & $72,41 \%$ & $65,62 \%$ & $71,42 \%$ & $74,07 \%$ \\
3 & $68 \%$ & $80 \%$ & $75,86 \%$ & $78,12 \%$ & $82,14 \%$ & $77,77 \%$ \\
4 & $84 \%$ & $90 \%$ & $93,1 \%$ & $87,5 \%$ & $92,85 \%$ & $92,59 \%$ \\
\hline
\end{tabular}

Sejalan dengan jumlah rerata nyamuk yang kontak dengan hewan uji, persentase daya proteksi juga mengalami peningkatan. Pada hasil 
perhitungan daya proteksi ini didapatkan bahwa semakin tinggi konsentrasi pada kelompok perlakuan, semakin tinggi juga daya proteksinya. Analisis probit dapat memberikan informasi mengenai estimasi besar konsentrasi yang memiliki daya proteksi ekstrak buah mahkota dewa terhadap nyamuk yang kontak dengan hewan coba. Penelitian ini menginginkan Effective Concentration (EC) dan Effective Time (ET) sebesar $50 \%$ yang dapat dilihat pada gambar 1 dan 2 .

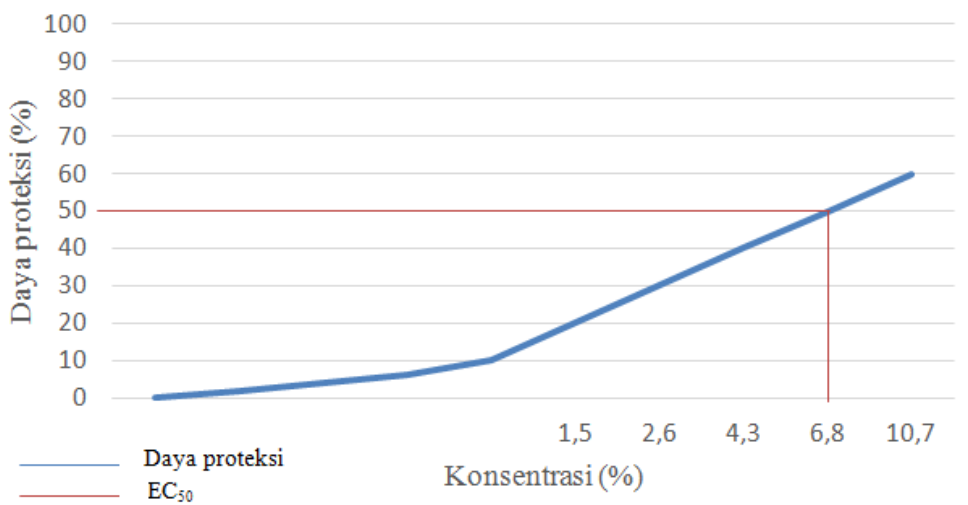

\section{Gambar 1. Persentase Konsentrasi Efektif Ekstrak Buah Mahkota Dewa Terhadap Nyamuk Aedes aegypti Yang Kontak Dengan Hewan Coba}

Pada $\mathrm{EC}_{50}$ didapatkan hasil bahwa pada $50 \%$ populasi, konsentrasi ekstrak mahkota dewa yang efektif yaitu dengan konsentrasi 6,83\%. Pada penelitian ini juga dilihat Effective Time $50 \%$, hasilnya pada $50 \%$ jumlah sampel ekstrak buah mahkota dewa akan efektif pada menit ke-38.

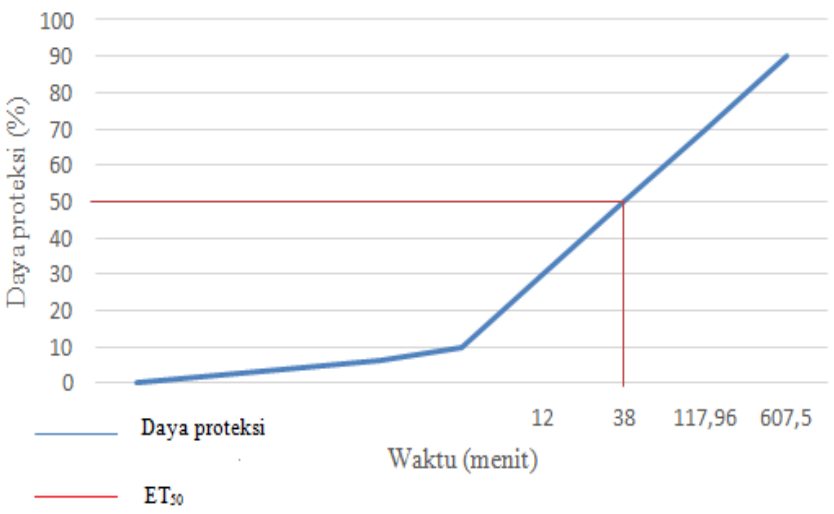

Gambar 2. Persentase waktu efektif ekstrak mahkota dewa terhadap nyamuk Aedes aegypti yang kontak dengan hewan coba 


\section{PEMBAHASAN}

Hasil perhitungan daya proteksi menunjukkan bahwa semakin tinggi konsentrasi maka semakin sedikit jumlah nyamuk yang kontak pada hewan coba sehingga semakin tinggi daya proteksinya. Senyawa yang terkandung didalam buah mahkota dewa seperti alkaloid, saponin, flavonoid, dan minyak atsiri. ${ }^{8}$ Senyawasenyawa tersebut bekerja dengan memanipulasi penghidu nyamuk melalui bau dari kulit yang telah dioleskan dengan ekstrak buah mahkota dewa sehingga menghambat sistem penghiduan nyamuk Aedes aegypti yang pada akhirnya nyamuk tidak mendekati kulit hewan coba (Simanjuntak, 2008).

Pengujian ekstrak buah mahkota dewa sebagai repelan terhadap nyamuk Aedes aegypti sesuai dengan dasar penelitian yang menyatakan bahwa sebagian besar tanaman memiliki hasil metabolit sekunder yang berupa senyawa aktif yang berfungsi sebagai penghalau serangga, dalam hal ini merupakan minyak atsiri yang merupakan salah satu senyawa pada mahkota dewa (Rinayanti, 2013).

Pada penelitian lain menunjukkan daya proteksi dan konsentrasi yang berbeda dari setiap tanaman uji yang digunakan. Selain itu terdapat juga perbedaan daya proteksi tertingginya. Hal ini terlihat pada penelitian Medikanto dan Setyaningrum (2013), menggunakan ekstrak daun legundi (Vitex trifolia $L$ ) dengan konsentrasi $30 \%$ memberikan daya proteksi $90,4 \%$. Penelitian Dwi Ario (2015) menggunakan ekstrak daun jambu biji merah dengan konsentrasi $50 \%$ memberikan daya proteksi $84,61 \%$. Penelitian Manurung (2013), menggunakan ekstrak perasan serai wangi dengan konsentrasi $4 \%$ memberikan daya proteksi $100 \%$ terhadap gigitan nyamuk Aedes aegypti. Selain itu penelitian sari (2012) meneliti tentang potensi ekstrak bawang putih dengan konsentrasi 30\% memberikan daya proteksi $90,4 \%$ (Tabel 3 ).

Tabel 3. Penelitian Daya Proteksi Dari Beberapa Ekstrak Tanaman Diujikan Oleh Peneliti lain Sebagai Repelan Nyamuk Aedes aegypti

\begin{tabular}{|c|c|c|c|c|c|}
\hline $\begin{array}{c}\text { Peneliti, } \\
\text { Tahun }\end{array}$ & $\begin{array}{c}\text { Ekstrak } \\
\text { Tumbuhan }\end{array}$ & $\begin{array}{c}\text { Senyawa } \\
\text { Aktif }\end{array}$ & $\begin{array}{c}\text { Konsentrasi } \\
\text { Efektif }\end{array}$ & $\begin{array}{c}\text { Daya } \\
\text { Proteksi }\end{array}$ & $\begin{array}{c}p- \\
\text { value }\end{array}$ \\
\hline $\begin{array}{l}\text { Medikanto \& } \\
\text { Setyaningrum, } \\
2013\end{array}$ & Daun legundi & $\begin{array}{l}\text { Flavanoid, } \\
\text { camphene, } \\
\text { pinene, } \\
\text { tannin, } \\
\text { phytosteroids, } \\
\text { saponin, } \\
\text { minyak atsiri }\end{array}$ & $30 \%$ & $90,4 \%$ & $<0,05$ \\
\hline Sari, 2012 & Bawang putih & Terpenoid & $30 \%$ & $91 \%$ & $<0,05$ \\
\hline $\begin{array}{l}\text { Manurung } \\
d k k, 2014\end{array}$ & Serai wangi & Minyak atsiri & $4 \%$ & $100 \%$ & $<0,05$ \\
\hline Ario, 2015 & $\begin{array}{l}\text { Daun jambu } \\
\text { biji }\end{array}$ & $\begin{array}{l}\text { Alkaloid, } \\
\text { saponin, } \\
\text { tannin, } \\
\text { flavonoid, } \\
\text { fenol }\end{array}$ & $50 \%$ & $84,61 \%$ & $<0,05$ \\
\hline
\end{tabular}

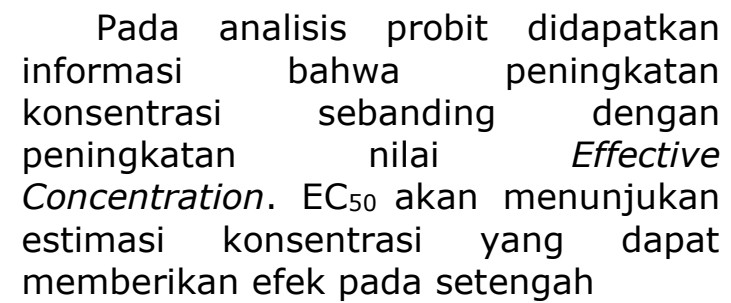

jumlah sampel yang diujikan. Penelitian ini memberikan hasil bahwa ekstrak buah mahkota dewa memiliki pengaruh sebagai repelan terhadap nyamuk Aedes aegypti dengan $\mathrm{EC}_{50}$ pada konsentrasi $6,830 \% \%$ yang telah melewati konsentrasi terendah 
pada penelitian ini yaitu konsentrasi $12,5 \%$. Hal ini menunjukkan daya proteksi ekstrak buah mahkota dewa sebagai repelan memiliki pengaruh.

Semakin rendah nilai $\mathrm{EC}_{50}$ suatu zat berarti zat tersebut memiliki pengaruh yang tinggi dalam menolak hewan yang diuji kontakkan. Oleh karena itu dapat disimpulkan bahwa ekstrak buah mahkota dewa mempunyai daya proteksi yang bermakna sebagai repelan. Effective Time $50 \%$ (ET50) menunjukkan estimasi waktu yang dapat memberikan efek pada setengah jumlah sampel yang diujikan. Penelitian ini memberikan hasil bahwa ekstrak mahkota dewa memiliki pengaruh sebagai repelan terhadap nyamuk Aedes aegypti dengan $\mathrm{ET}_{50}$ pada waktu 38 menit setelah pengaplikasian losion ekstrak mahkota dewa ke hewan coba.

\section{KESIMPULAN}

Berdasarkan penelitian yang telah dilakukan dapat disimpulkan bahwa Ekstrak mahkota dewa (Phaleria macrocarpa) efektif sebagai repelan terhadap nyamuk Aedes aegypti. Waktu dan konsentrasi ekstrak mahkota dewa yang efektif sebagai repelan pada hewan coba yaitu pada menit ke-38 pengaplikasian lotion dengan konsentrasi $6,83 \%$.

\section{SARAN}

Pada penelitian selanjutnya diharapkan dapat menemukan loka penelitian dengan sertifikat galur nyamuk yang steril sehingga dapat menggunakan sampel uji dengan lengan manusia. Pada penelitian selanjutnya juga diharapkan dapat meneliti kadar masing-masing kandungan yang terdapat pada buah mahkota dewa.

\section{DAFTAR PUSTAKA}

Aulia SD, Setyaningrum E dan Wahyuni A. (2013). Efektivitas ekstrak buah mahkota dewa merah (Phaleria macrocarpa (Scheff.)Boerl) sebagai ovisida Aedes aegypti. Juke UNILA. $1: 8$.
Harmanto N. (2004). Mahkota dewa obat pusaka indonesia. Jakarta: PT Mahkota Dewa Indonesia.

Mustanir \& Marianne. (2011). Aktivitas repellent nyamuk lotion kombinasi ekstrak batang Vitex trifolia I. dan n,n-dietil-meta-toluamida. Jurnal Farmasi Indonesia. 5(4):172-9.

Novizan I. (2002). Membuat dan memanfaatkan pestisida ramah lingkungan. Edisi 1. Tangerang: PT Agromedia Pustaka.

Perkins DJ. (2011). Severe malaria anemia: innate immunity and pathogenesis.int. j. biol. Sci7 (9):1427-42.

Rinayanti A dan Dewanti E. (2013). Phaleria macrocarpa( Scheff) boerl terhadap mencit putih (Mus musculus 1 ). Jurnal Farmasi Indonesia. 1:40-7.

Simanjuntak P. (2008). Identifikasi senyawa kimia dalam buah mahkota dewa (Phaleria macrocarpa) thymelaeaceae. Jurnal ilmu Kefarmasian Indonesia. 6(1):49-54.

Sofian FF, Runadi D, Tjitraresmi A, Arwa, Pratama G. (2016). Aktivitas repelen kombinasi minyak atsiri rimpang bengle (Zingiber cassumunar roxb.) dan daun sereh wangi (Cymbopogon nardus (I.) rendle) terhadap nyamuk Aedes aegypti. Farmaka. 14(2):1-12.

WHO. (2012). Treatment, Prevention And Control Global Strategy For Dengue Prevention And Control. Geneva: WHO Library Cataloguing Data.

WHOPES. (2000). Control Of Neglected Tropical Diseases Who Pesticide Evaluation Scheme: Guidelines For Efficacy Testing of Mosquito Repellents For Human Skin. Geneva: WHO. 